J. Lake Sci.(湖泊科学), 2022, 34(2): 675-683

DOI 10. 18307/2022. 0226

(C) 2022 by Journal of Lake Sciences

\title{
太湖流域长荡湖近百年生态环境演变过程”
}

\author{
刘维涂 ${ }^{1}$,林 琪 ${ }^{2,3}$, 张 科 ${ }^{2,3}$, 沈 吉 ${ }^{1,3 * *}$ \\ ( 1 : 南京大学地理与海洋科学学院,南京 210023) \\ (2: 中国科学院南京地理与湖泊研究所,南京 210008) \\ (3:湖泊与环境国家重点实验室, 南京 210008)
}

\begin{abstract}
摘 要: 社会经济转型产生的多重人为驱动力对太湖流域的生态环境和服务功能造成了深远的负面影响. 湖泊沉积记录 有助于探索流域人与环境长期相互作用过程, 为生态修复提供理论支撑. 本研究通过对太湖流域长荡湖沉积岩芯有机 质、营养盐和重金属元素等指标的系统分析, 在 ${ }^{210} \mathrm{~Pb}$ 定年结果的基础上, 结合地球化学标准化方法以及流域人类活动资 料, 解析了近 100 年来湖泊的富营养化和重金属污染过程、特征与主要驱动因素. 结果显示, 长荡湖岩芯沉积指标呈相似 的三阶段历史变化, $1950 \mathrm{~s}$ 之前, 沉积物有机碳、总氮和磷较为稳定, 湖泊营养水平较低, 对应人类活动影响较弱的准自然 演化阶段; 随后湖泊进人人为主导的过渡阶段, 特别是在 $1970 \mathrm{~s}$, 湖泊营养水平、藻类生产力以及重金属污染程度 $(\mathrm{Cd}>>$ $\mathrm{Sb}>\mathrm{Cu} \approx \mathrm{Pb} \approx \mathrm{Zn}$ ) 均显著升高, 直接受到流域人口增加、农业集约化、工业化和城镇化导致的污染排放的影响. 1980s 以 后, 类似于太湖流域大多数湖泊, 长荡湖已经大幅偏离自然演化基线, 处于高度富营养化、重污染的状态, 威胁流域生态 安全. 本研究进一步指出, 深人理解湖泊生态环境历史演变过程及人为影响有助于湖泊一流域系统的可持续管理.
\end{abstract}

关键词: 富营养化; 重金属污染; 人类活动;沉积物;太湖流域;长荡湖

\section{Eco-environmental evolutionprocess during the past century in Lake Changdang, Lake Taihu Basin *}

\author{
Liu Weigan ${ }^{1}$, Lin $\mathrm{Qi}^{2,3}$, Zhang $\mathrm{Ke}^{2,3}$ \& Shen $\mathrm{Ji}^{1,3 * *}$ \\ (1: School of Geography and Ocean Science, Nanjing University, Nanjing 210023, P.R.China) \\ (2: Nanjing Institute of Geography and Limnology, Chinese Academy of Sciences, Nanjing 210008, P.R.China) \\ (3: State Key Laboratory of Lake Science and Environment, Nanjing 210008, P.R.China)
}

\begin{abstract}
Multiple anthropogenic stressors generated by the socioeconomic transitions have far-reaching negative impacts on the water environment and ecosystem services in the Lake Taihu Basin. Lake sediment records contribute to exploring the interactions between humans and the environment and supporting the ecological restoration in catchments. Based on the analyses of sedimentary organic matter, nutrients and major heavy metal elements in the core of Lake Changdang in the Lake Taihu Basin, combining with ${ }^{210} \mathrm{~Pb}$ dating results, geochemical normalization and historical documents of human activity in the catchment, this study explored the processes, characteristics and main driving factors of lake eutrophication and heavy metal pollution over the past 100 years. The results show that multiple cores proxies have similar three-stage historical changes. Before the $1950 \mathrm{~s}$, sediment organic carbon, total nitrogen and phosphorus were relatively stable, and lake nutrient level was low, corresponding to the quasi-natural evolution phase with the weak influence of human activities. Subsequently, the lake entered into a transition phase dominated by human impacts. Particularly in the 1970 s, lake nutrient level, algal productivity and heavy metal pollution $(\mathrm{Cd}>>\mathrm{Sb}>\mathrm{Cu} \approx \mathrm{Pb} \approx \mathrm{Zn})$ increased significantly, which were directly affected by the pollutant discharge resulted from the increase in population, agricultural intensification, industrialization and urbanization in the catchment. Since 1980s, Lake Changdang has deviated from the natural evolution baseline and maintained a state of high eutrophication and heavy pollution, threatening the ecological security of the catchment. This study further highlights that understanding the historical process of lake eco-environmental evolution and anthropogenic
\end{abstract}

* 2021-05-14 收稿;2021-08-07 收修改稿.

国家重点研究发展项目 (2017YFA0606200) 和江苏省自然科学基金青年项目(BK20201099)联合资助.

** 通信作者;E-mail: jishen@ nju.edu.cn. 
impacts helps sustainable lake catchment management.

Keywords: Eutrophication; heavy metal pollution; human activity; sediment; Lake Taihu Basin; Lake Changdang

太湖流域位于长江下游,近千年来一直是中国经济最发达、人口最密集的地区之一 ${ }^{[1]}$. 最近几十年,太 湖流域经历了快速的农业发展、城市化和工业化 ${ }^{[2]}$. 虽然太湖流域仅占国土面积的 $0.4 \%$,但其 GDP 约占到 全国的 9.8\% , 人口约占到全国的 4.4\% (>6千万居民), 对我国社会经济发展和生态文明建设具有重要意 $义^{[3]}$. 过度开发已经对太湖流域的生态环境产生了深远的负面影响, 使其难以满足当前可持续发展对流域 生态系统服务和功能的需求 ${ }^{[2]}$. 多重人为影响如森林砍伐、土地开剭、农业化肥的使用以及工农业废水排放 使湖泊水质显著恶化 ${ }^{[4]}$, 主要表现在两方面: 第一, 富营养化严重, 蓝藻水华暴发增强, 如暴发面积加大、频 次升高、时间延长; 第二, 重金属等典型人为污染加剧, 不仅具有易富集、难降解、高毒性等特点, 还会通过生 物积累和食物链放大作用对水生群落造成危害,进一步危及水产品安全和人类健康 ${ }^{[5]}$.

长荡湖是太湖流域的第三大湖泊, 位于流域上游. 该湖泊兼具灌溉、养殖、供水等多种功能, 并作为金坛 和溧阳等城市饮用水的备用水库, 是太湖上游重要的水源地之一. 近年来, 受到农业、养殖业发展以及工业 化和城镇化的影响, 长荡湖流域水环境总体呈下降趋势, 湖体已达到中一重度富营养状态 ${ }^{[6-7]}$. 水质监测数据 表明, 在 1997-2012 年间, 长荡湖水体总氮浓度变化范围为 $0.363 \sim 7.685 \mathrm{mg} / \mathrm{L}$, 总磷浓度为 $0.046 \sim 0.317$ $\mathrm{mg} / \mathrm{L}^{[6]} .2010$ 年长荡湖叶绿素 $a$ 平均浓度已达 $50 \mu \mathrm{g} / \mathrm{L}$, 高于太湖流域大多数水体, 并呈持续上升趋势 ${ }^{[7]}$; 目前, 长荡湖局部水体受到严重富营养化、蓝藻水华暴发的影响, 直接威胁流域生态安全. 然而, 通过监测和 调查手段获取的数据通常时间太短或范围有限, 无法提供湖泊生态环境变化的全面记录, 难以重建人类改 造湖泊的完整历史过程, 不利于湖泊生态环境的有效保护和湖泊资源的可持续利用 ${ }^{[8]}$.

湖泊沉积作为湖泊一流域物质的 “汇”, 具有连续性好、时间分辨率高、蕴含信息量丰富等特点, 是了解 过去湖泊环境质量演变的重要媒介, 同时也成为研究人与自然相互作用历史及区域生态环境重建的良好载 体 ${ }^{[9-10]}$. 基于精确定年的湖泊沉积记录, 有效揭示了我国东部发达地区的巢湖、鄱阳湖、太湖等大型浅水湖泊 近百年来人为污染和富营养化历史 ${ }^{[11-14]}$; 近年来太湖流域其他较小湖泊的古湖沼研究也揭示出流域人类活 动对过去湖泊环境变化存在强烈影响, 并强调了湖泊沉积记录在研究人与环境相互作用过程、支撑流域生 态安全中的重要作用 ${ }^{[15-17]}$. 本研究旨在通过对长荡湖沉积岩芯中的有机质、营养盐和金属元素开展系统分 析, 结合流域社会经济发展资料, 解析湖泊过去百年来的富营养化和重金属污染历史及特征, 反演湖泊生态 环境演变过程, 以期为流域环境评价和生态修复提供更多基础数据支撑.

\section{1 材料与方法}

\section{1 研究区概况}

长荡湖 ( $31^{\circ} 33^{\prime} \sim 31^{\circ} 40^{\prime} \mathrm{N}, 119^{\circ} 30^{\prime} \sim 119^{\circ} 37^{\prime} \mathrm{E}$ ) 位于太湖流域西北部 (图 1). 该区域受到亚热带季风影 响, 四季分明, 年降水量在 1000 1400 mm 之间, 多年平均降水量为 $1115.1 \mathrm{~mm}$, 降雨主要集中于 5-9 月 ${ }^{[18]}$. 长荡湖长 $16.0 \mathrm{~km}$, 宽 $5.6 \mathrm{~km}$, 水域面积约 $90 \mathrm{~km}^{2}$, 水深 $0.8 \sim 1.2 \mathrm{~m}, \mathrm{pH}$ 值为 7 8, 年均进出长荡湖水量为 $6 \times$ $10^{8} \sim 7 \times 10^{8} \mathrm{~m}^{3} / \mathrm{a}$, 换水周期为 $56 \mathrm{~d}^{[18]}$. 长荡湖水文情况复杂, 有 12 条相连的河流, 大部分从西部人湖, 向东 排人滆湖水系, 最终汇人太湖 ${ }^{[18]}$. 其中丹金溧漕河来源于京杭大运河, 纵贯金坛区, 是流域最大的人湖河 流, 汇集了通济河和薛埠河等河流后分流注人湖泊 (图 1). 过去 50 多年来, 长荡湖区域经历了快速的人口增 长和经济发展, 其中金坛区人口从 1950 年的 27 万增加到 2016 年的 55 万, 同期年工业产值从 200 万元增加 到 1218 亿元 ${ }^{[19]}$; 然而, 流域生态环境受到强烈人为影响, 湖泊水质显著恶化.

\section{2 样品采集、实验分析与数据收集}

长荡湖湖心区的沉积物未受到人为活动的直接干扰, 具有连续的沉积序列. 在 2016 年, 利用配备 $90 \mathrm{~mm}$ 直径取芯管的接杆采样器, 在长荡湖湖心区 (图 1) 采集了长 $50 \mathrm{~cm}$ 沉积岩芯, 所获岩芯水土界面清晰; 现场 以 $0.5 \mathrm{~cm}$ 间隔分样, 所有样品均置于密封袋内冷藏保存, 带回实验室以备分析. Zhang 等 ${ }^{\left[{ }^{[16]}\right.}$ 报道了该岩芯沉 积物的 ${ }^{210} \mathrm{~Pb}$ 年代序列, 结果表明, $50 \mathrm{~cm}$ 岩芯涵盖了长荡湖过去 111 年的沉积历史 (1905-2016 年), 平均沉 积速率为 $0.45 \mathrm{~cm} / \mathrm{a}^{[16]}$, 这与太湖和长江中下游其他湖泊的研究结果较为一致 ${ }^{[13,20]}$. 


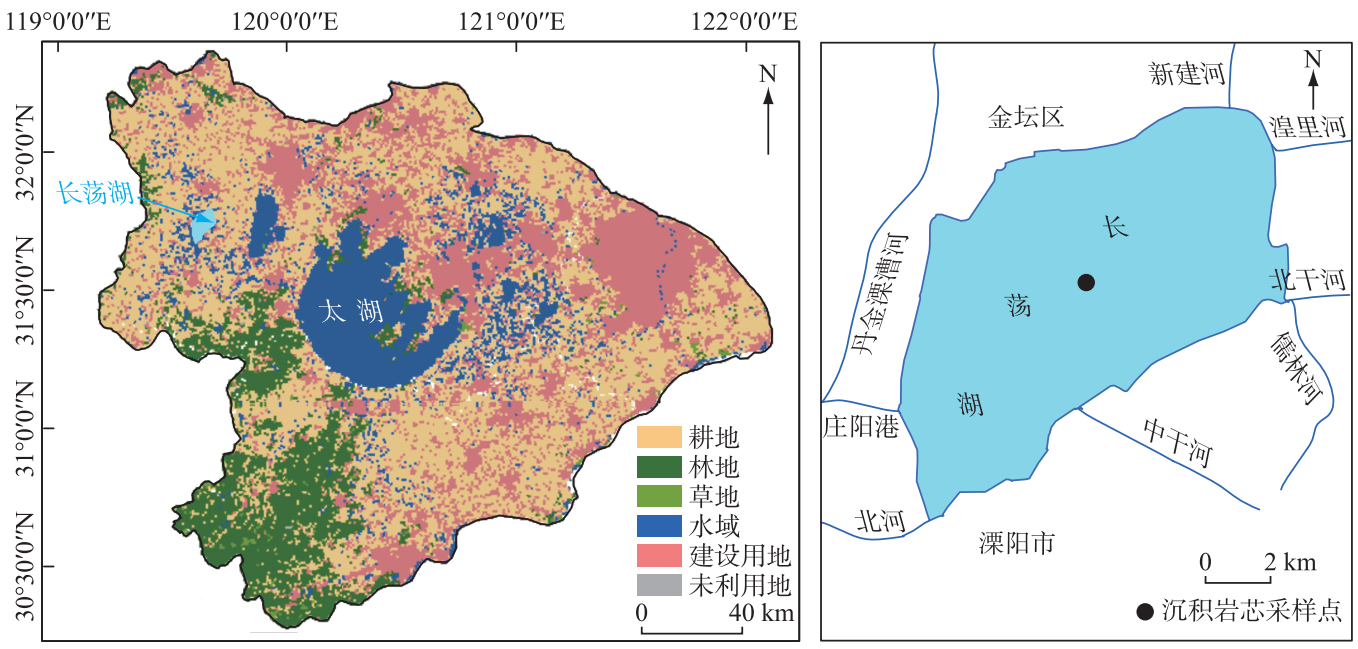

图 1 太湖流域土地利用方式和长荡湖岩芯采样点位置

Fig.1 Land use types in Lake Taihu Basin and a sampling site of the sediment core in Lake Changdang

岩芯样品冷冻干燥后, 被磨过笁 (孔径为 $0.074 \mathrm{~mm}$ ), 主要用于分析沉积物中有机质、营养盐和金属元素 含量, 分析间隔为 $1 \sim 2 \mathrm{~cm}$. 取约 $0.5 \mathrm{~g}$ 样品, 加人足量 $5 \%$ 的稀盐酸充分反应以去除碳酸盐, 用去离子水洗至 中性, 冷冻干燥后, 称重和研磨, 采用 EA3000 型元素分析仪测定样品中的总有机碳( TOC) 和总氮 ( TN) 含量. 每 15 个样品插人质控标样, 即地质矿产部地球物理地球化学勘查研究所提供的土壤和水系沉积物, 确保分 析误差 $<10 \%$. 取约 $0.2 \mathrm{~g}$ 样品, 经盐酸一硝酸一氢氟酸完全消解, 采用电感耦合等离子体原子发射光谱仪 (ICP-AES) 测定金属元素 $\mathrm{Al} 、 \mathrm{Zn}$ 和总磷 ( TP) 含量, 采用电感耦合等离子体质谱仪 (ICP-MS) 测定微量金属 元素 $\mathrm{Cr} 、 \mathrm{Ni} 、 \mathrm{Cu} 、 \mathrm{~Pb} 、 \mathrm{Zn} 、 \mathrm{Sb} 、 \mathrm{Cd}$ 等含量. 分析过程中每 10 个样品采用空白对照和标准参考物质 GBW07309 进 行质量控制, 测量精度控制在 $92 \% \sim 106 \%$ 范围内. 所有样品测试均在中国科学院南京地理与湖泊研究所湖 泊与环境国家重点实验室完成.

长荡湖流域近 60 年来连续的社会和经济记录主要收集自金坛区统计年鉴和地方志,包括人口、农作物 和水产品产量以及化工和冶金产值等数据,用于反映流域人类活动的长期趋势.

\section{3 沉积物污染评价方法}

本文采用地球化学方法对长荡湖沉积物重金属元素进行标准化, 以消除粒度效应和有机质对重金属含 量的影响, 准确评估人为污染. 沉积物中 $\mathrm{Al}$ 元素通常以流域自然来源为主, 地球化学性质稳定, 其含量可以 指示流域物源区土壤与岩石碎屑供给的变化 ${ }^{[21-22]}$. 本文选取 $\mathrm{Al}$ 作为参比元素, 目标元素 $\mathrm{M}$ 含量经地球化学 标准化后,其富集系数 $(E F)$ 计算公式为:

$$
E F=(\mathrm{M} / \mathrm{Al})_{\text {样品 }} /(\mathrm{M} / \mathrm{Al})_{\text {背景 }}
$$

为定量反映沉积物中重金属的人为贡献量, 本文进一步计算了目标重金属的人为来源含量 $[\mathrm{M}]$ 人为, 其 公式为 ${ }^{[13]}$ :

$$
[\mathrm{M}]_{\text {人为 }}=[\mathrm{M}]_{\text {样品 }}-[\mathrm{Al}]_{\text {样品 }} \times(\mathrm{M} / \mathrm{Al})_{\text {背景 }}
$$

沉积物背景值的选取直接影响到富集系数的计算结果. 研究表明,在进行湖泊等较小水体单元沉积物 重金属污染评价时,历史沉积物更为合适 ${ }^{[21]}$. 根据长荡湖沉积岩芯测年结果和重金属含量垂向变化特征, 本研究选取沉积岩芯底部 5 个样品 (相当于 1905-1915 年) 中金属元素含量平均值作为参考背景. 由此, 本 文中计算的重金属 $E F$ 值可有效指示人为污染程度,其中 $E F<2$ 指示无污染至较低污染, $2 \sim 5$ 指示中等污染 程度, $5 \sim 20$ 指示高污染程度, $>20$ 指示极高污染程度 ${ }^{[23-24]}$.

此外, 本研究采用污染负荷指数 (PLI) 来评估单个样品 (特定年代的沉积层位) 中重金属总的污染水平, 计算公式为 ${ }^{[25]}$ : 


$$
\begin{gathered}
P L I=\left(C F_{1} \cdot C F_{2} \cdot C F_{3} \cdots C F_{n}\right)^{1 / n} \\
C F=[\mathrm{M}]_{\text {样品 }} /[\mathrm{M}]_{\text {背景 }}
\end{gathered}
$$

式中, $\mathrm{M}$ 为目标重金属元素, $C F$ 为重金属的污染系数. 本文分析沉积物中 $\mathrm{Cr} 、 \mathrm{Ni} 、 \mathrm{Cu} 、 \mathrm{~Pb} 、 \mathrm{Zn} 、 \mathrm{Sb} 、 \mathrm{Cd}$ 共 7 种重 金属元素的综合污染水平,重建湖泊污染历史序列. 当 $P L I>1$ 时,即指示存在重金属污染.

\section{2 结果与讨论}

\section{1 沉积物营养盐与湖泊富营养化}

在亚热带浅水湖泊中, 沉积物 TOC、TN 和 TP 含量通常与湖泊的生产力和营养状况密切相关, 是湖泊富 营养化过程重建的重要指标 ${ }^{[26]}$. 湖泊沉积物中 TOC 主要有 2 种来源, 即以湖泊自身水生生物 (细菌、藻类和 大型水生植物等) 为主的内源贡献和以流域内陆生植被及土壤来源为主的陆源贡献; TN 主要以有机氮的形 式存在, 自然条件下以湖泊生物来源为主, 部分受干扰湖泊中也存在人为活动输人 ${ }^{[27]}$. 湖泊沉积物中有机 质的碳氮摩尔比值 $(\mathrm{C} / \mathrm{N})$ 可以较好地判识有机物的来源. 研究表明, 低等水生植物 (藻类) 及光合细菌具有 较低的 C/N 比值,一般介于 4 10; 陆生维管束植物具有较高的 $\mathrm{C} / \mathrm{N}$ 比值, 一般 $>20$; 大型水生植被的 $\mathrm{C} / \mathrm{N}$ 比 值一般介于 $10 \sim 20$ 之间 ${ }^{[28]}$. 当沉积物中有机质的 $\mathrm{C} / \mathrm{N}$ 比值大于 8 时, 常常被认为是受到陆源输人或水生植 被影响; 沉积物中内源有机质所占的比例越高, $\mathrm{C} / \mathrm{N}$ 比值就越小 ${ }^{[29]}$. 磷被视为大多数湖泊中藻类生长的主 要限制性营养盐, 磷输人直接影响到湖泊的营养状态 ${ }^{[30]}$. 湖泊沉积物中磷一般有 2 种来源: 一是流域土地利 用与地表植被破坏, 导致土壤侵蚀, 自然源磷输人湖泊, 并以颗粒态为主, 难以被生物直接吸收利用; 二是流 域居民生活废水、农业污水排放等人为源的磷, 主要以溶解态进人湖泊, 大部分以生物可利用态蓄积于沉积 物中 ${ }^{[30]}$.

长荡湖岩芯沉积物中 TOC、TN 和 TP 含量的变化趋势大体相似, 分别由岩芯底部到顶部呈现相对平稳、 显著上升、维持在较高水平或稍有下降趋势, 而 $\mathrm{C} / \mathrm{N}$ 比值呈相反的变化趋势. 整体上, 沉积物营养指标历史 变化与流域社会经济记录相对应 (图 2), 例如, 1950 年以来 TOC、TN 含量与农作物产量的相关系数分别为 0.671 和 0.682 , 与水产品产量的相关系数分别为 0.697 和 0.742 , 均表现出显著相关. 因此, 长荡湖富营养化 过程大致可以划分为 3 个阶段:

第一阶段 (1905-1950s), TOC、TN 和 TP 含量相对平稳, 均维持在较低水平, 可能指示该时期湖泊初级 生产力较低; $\mathrm{C} / \mathrm{N}$ 比值介于 12.8 15.3(平均为 14.0), 整体处于 3 个阶段中最高水平, 反映此时沉积物中有 机质受到内源与外源的共同影响, 特别可能与该时期相对发育的水生植被有关 ${ }^{[31]}$. $1950 \mathrm{~s}$ 以前, 长荡湖流域 以传统农业为主, 金坛县 $90 \%$ 以上的人口从事粗放式农业活动, 生产技术相对落后 ${ }^{[32]}$. 根据营养指标综合 判识,该阶段湖泊生态环境受人类活动影响较弱, 湖泊营养水平相对较低.

第二阶段 (1950s-1980s), TOC 和 TN 含量均呈上升趋势, 并在 1970s 翻倍, C/N 比值持续下降至 9 左 右, 指示湖泊沉积物有机质增多, 以内源贡献为主, 其所占比重逐渐升高. 该阶段最大的特征是: TP 含量在 $1970 \mathrm{~s}$ 急剧升高至 $2050 \mathrm{mg} / \mathrm{kg}$, 显示湖泊营养水平快速上升, 以藻类为主的初级生产力急剧增强. 这与流域 农业活动及居民生活等产生的营养物质输人增加密切相关. 在此阶段, 长荡湖流域人口翻倍, 到达 50 万以 上; 流域居民开展了大规模的农业垦殖, 超过 $20 \%$ 的流域土地被开垦为农业用地, 含磷肥料被大量使用, 以 满足日益增长的粮食和农产品需求, 致使湖泊出现快速的营养富集和生态恶化, 如由草型清水湖泊向藻型 浊水湖泊过渡 ${ }^{[15]}$.

第三阶段 (1980s-2016 年), TOC 和 TN 含量处于较高水平, 略呈上升趋势, C/N 比稍有下降, 指示湖泊 处于高藻类生产力的状态, 这与先前基于沉积物脂类生标的研究结果一致 ${ }^{[16]}$. TP 含量虽有短期快速下降, 但仍处于较高水平, 可能受到农业磷输人减少和有机磷占比下降的影响, 同时沉积物底泥释放的磷会对湖 泊水体产生二次营养输人. 与上一阶段相比, 长荡湖流域社会从农业主导型转变为工业型为主, 丹金溧漕河 携带大量工业和城镇化产生的污水进人湖泊, 造成持续的人为营养和污染物输人, 维持甚至加剧湖泊富营 养化程度. 根据 2001-2002 年长荡湖出人湖泊的流量监测资料显示, 由河道人湖的 TN 和 TP 负荷分别达到 3389.4 和 $88.0 \mathrm{~T} / \mathrm{a}$, 占总人湖负荷的 $62.3 \%$ 和 $49.2 \%{ }^{[33]}$. 此外, $1980 \mathrm{~s}$ 长荡湖的围网养殖面积接近全湖面积 的一半 ${ }^{[34]}$, 水产品产量从 1970 年的 $2300 \mathrm{t}$ 增长到 2007 年的 $44460 \mathrm{t}$, 人工投放饵料带人了大量的氮、磷等营 


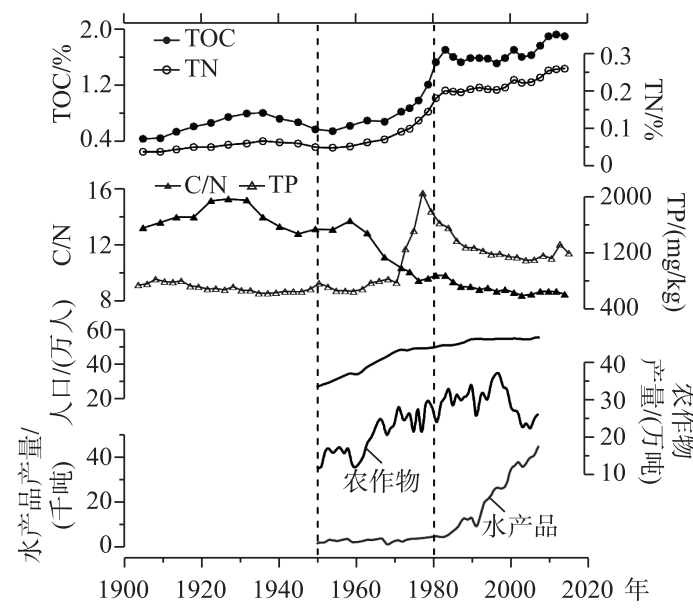

图 2 长荡湖岩芯沉积物有机质和营养盐指标 $(\mathrm{TOC} 、 \mathrm{TN} 、 \mathrm{C} / \mathrm{N} 、 \mathrm{TP})$ 与 流域人口、农作物及水产品产量历史变化对比

Fig.2 Historical variations of nutrient proxies ( TOC, TN, C/N, TP) of sediment core in Lake Changdang and population, crop and aquatic yield within the catchment

养物质 ${ }^{[35]}$. 例如, 由养殖业带来的 TP 达到 $27.0 \mathrm{t} / \mathrm{a}$, 占人湖污染负荷的 $15.1 \%{ }^{[2]}$. 在人为营养富集和水位调 节的双重作用下, 长荡湖水体透明度从 2005 年的 $0.52 \mathrm{~m}$ 降低到 2012 年的 $0.33 \mathrm{~m}$, 叶绿素 $a$ 浓度升高至 $50 \sim 100 \mu \mathrm{g} / \mathrm{L}$ 范围, 而沉水植被覆盖度从 $1980 \mathrm{~s}$ 初的 $84 \%$ 锐减至 $2010 \mathrm{~s}$ 初的 $30 \%$ 以下 ${ }^{[4-5]}$, 湖泊进人生态急 剧退化的藻型状态.

最近数十年来, 一系列环境保护措施在长荡湖实施, 如退田还湖、减少围网养殖规模、拦污截留等, 但湖 泊沉积物营养盐指标并未出现明显变化, 水体氮磷仍超出地表水 III 类水质标准, 蓝藻水华时有发生. 因此, 长荡湖当前管理工作亟待加强相关保护和修复措施的力度, 调控藻型富营养化湖泊的内在营养循环, 制定 合理的修复目标和实施路径. 例如, 根据 1950 年之前的湖泊营养本底和水生群落组合, 可以确立切实可行 的修复策略.

\section{2 沉积物重金属污染与人为影响评估}

随着我国工业化和城市化的快速发展, 湖泊重金属污染问题越发严重 ${ }^{[36]}$. 重金属元素一般通过流域汇 水、地表径流和大气沉降进人湖泊中, 大部分经由悬浮物质的吸附和沉淀作用积累在沉积物中. 因此, 湖泊 沉积物能有效记录重金属污染历史, 评估人为影响程度, 并且为湖泊重金属污染治理提供背景参考 ${ }^{[13]}$. 如 图 3 所示, 长荡湖岩芯沉积物中的金属元素具有相似的历史变化模式, 含量均在 1970 年前后升高, 在 1980 年到达峰值, 随后稍有下降 (Cd 除外), 最后于 1990s 以后保持稳定, 说明近几十年金属元素来源发生了显著 变化. 从变异系数来看, 各重金属含量的离散程度都较大, 其中变异系数最大的是 $\mathrm{Cd}(129 \%)$, 远高于其他 元素,可能受输人影响最强,其次分别为 $\mathrm{Sb}(86 \%) 、 \mathrm{Cu}(55 \%) 、 \mathrm{Zn}(53 \%) 、 \mathrm{~Pb}(44 \%)$.

通过地球化学标准化, $E F$ 值能有效指示重金属的人为污染程度. 长荡湖沉积岩芯中 $\mathrm{Cr} 、 \mathrm{Ni}$ 的 $E F$ 值较 为稳定, 均接近于 1 , 说明二者以碎屑来源为主, 基本不受人为污染影响. $\mathrm{Cu} 、 \mathrm{~Pb}$ 和 $\mathrm{Zn}$ 的 $E F$ 值在 1970 年之 后约从 1 开始增加, 并在 $1980 \mathrm{~s}$ 初期达到并保持在 $2 \sim 3$ 之间, 即处于中等污染程度 ${ }^{[25]}$; $\mathrm{Sb}$ 的 $E F$ 值增加到 8 左右, 对应于高污染程度, 随后于 1990s 初期降低到中等污染程度. 然而, 沉积岩芯中 Cd 的 $E F$ 值自 1970 年 开始急剧上升, 至 $1990 \mathrm{~s}$ 初期到达 41 , 随后保持稳定, 指示了极高的人为污染水平. 本文运用人为源金属含 量进一步表征沉积物中重金属污染的人为贡献 (图 4), 结果表明, 人为 $\mathrm{Zn}$ 含量最高, 平均可达 $59.5 \mathrm{mg} / \mathrm{kg}$; 人为 $\mathrm{Cu}$ 和 $\mathrm{Pb}$ 含量次之, 均值分别为 15.8 和 $9.8 \mathrm{mg} / \mathrm{kg}$; 人为 $\mathrm{Cd}$ 和 $\mathrm{Sb}$ 含量最低, 均值分别为 1.9 和 $1.1 \mathrm{mg} /$ $\mathrm{kg}$. 由此说明, 长荡湖沉积物中重金属污染的蓄积量顺序为 $\mathrm{Zn}>\mathrm{Cu}>\mathrm{Pb}>\mathrm{Cd}>\mathrm{Sb}$, 这与流域人类活动导致的重 金属排放量密切相关. 


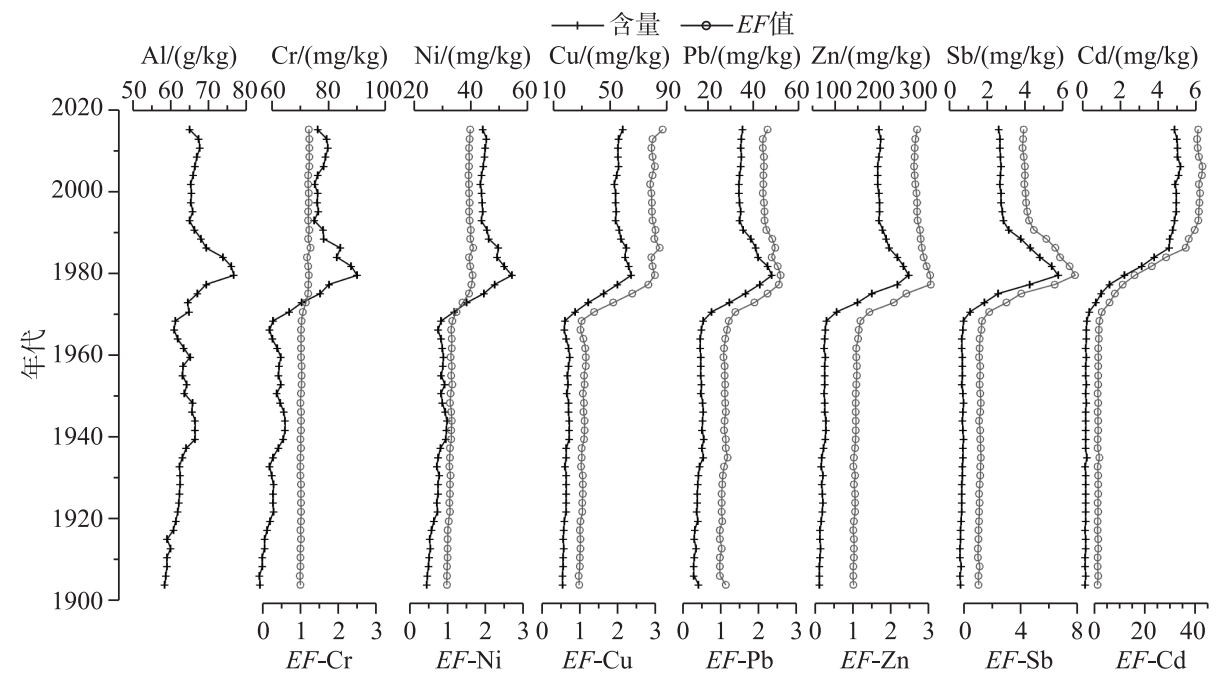

图 3 长荡湖沉积岩芯金属元素含量及富集系数 $(E F)$ 值的变化

Fig. 3 Changes in contents and $E F$ values of metals in the sediment core from Lake Changdang

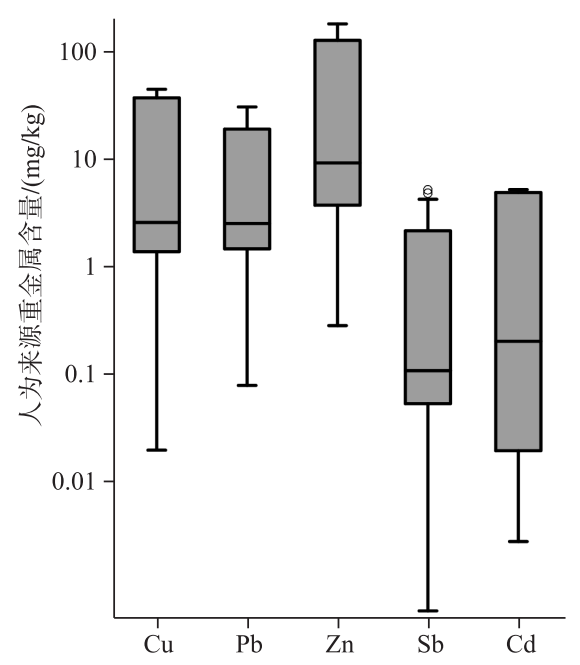

图 4 长荡湖沉积岩芯中人为 来源的重金属含量

Fig.4 Anthropogenic contents of heavy metals in the sediment core from Lake Changdang

湖泊、河流等水体沉积物中重金属污染通常以工业来 源和农业来源为主 ${ }^{[13,37]}$, 其输人途径包括: (1) 点源排放, 如工业污水排放等; (2) 面源污染, 如大气沉降、农业污水 等. 先前研究指出, 长江中下游等经济发达地区的湖泊中, 重金属污染受工业废水输人影响显著 ${ }^{[11,13]}$. 根据图 5 所 示, 1970 年开始长荡湖流域工业产值 (如化工和冶金产业) 持续上升, 特别是在 $1980 \mathrm{~s}$ 之后, 区域工业蓬勃发展, 与湖 泊重金属污染程度 ( $E F$ 和 $P L I$ 值) 的升高相对应, 很可能 反映了该时期粗放式发展模式下大量工业排污对湖泊环 境的不利影响. 例如, 长荡湖流域先后建立了金坛化肥厂、 钢铁厂、分析仪器厂、制糖厂、水泥厂等一批工业企业, 其 数量从 1949 年的 27 家增加到 1978 年的 768 家, 直至近年 的上千家 ${ }^{[19]}$. 该时期流域经济发展以乡镇工业为主, 环境 保护意识淡薄, 化工、冶金、机械制造等重工业以及纺织等 轻工业产生的污水含有大量重金属等毒害物质, 直接通过 丹金溧漕河等河流水系排人湖泊造成污染. 此外, 流域周 边车辆和船只的汽油燃烧、润滑油使用、轮胎和制动片磨 损等会产生重金属颗粒, 可能通过粉尘的沉降和径流携带 进人湖泊造成污染并累积 ${ }^{[38]}$. 其中, 较高的 $\mathrm{Sb}$ 污染可能主 要由化石燃料燃烧、冶金工业的发展造成 ${ }^{[13]}$. 长荡湖沉积 物中的 Cd 污染最为严重, 与西太湖类似 ${ }^{[13]}$, 呈现出极高的生态风险, 很可能是受到宜兴陶瓷工业蓬勃发展、 污染排放的影响 ${ }^{[39]}$. 虽然长荡湖流域农业发展轨迹与湖泊重金属污染历史存在差异, 但是 1980 年以来化 肥、农药的大量使用也会加剧沉积物中 $\mathrm{Sb} 、 \mathrm{Zn} 、 \mathrm{Cd}$ 等污染物的累积 ${ }^{[37,40]}$.

近 20 年来, 长荡湖重金属污染趋向稳定或稍有下降,可能受益于污染控制和环境治理投资等措施的实 行 $^{[41]}$. 在工业持续发展的同时, 加大污染治理可以有效提升环境质量. 例如, 2000 年以后, 长荡湖沉积岩芯 中 $\mathrm{Sb}$ 和 $\mathrm{Pb}$ 污染的降低, 可能与太湖流域煤燃烧减少、含铅汽油禁用等能源结构转型有关 ${ }^{[42]}$; 岩芯中 $\mathrm{Sb}$ 污 
染的降低,还可能与 1980s 以来太湖流域城市焚 烧炉的减少和老旧重污染冶金工业的淘汰转型 有关. 由此说明,相比于早期粗放式发展模式, 当 前先进技术应用、资源集约和环境友好的发展模 式有助于实现区域可持续发展 ${ }^{[43]}$. 同时, 湖泊中 $\mathrm{Cd}$ 等重金属和有机污染物仍处于较高水平 ${ }^{[44]}$, 直接威胁水生生物健康和水产品安全, 应当成为 环境管理与污染修复工作关注的重点. 太湖流域 排污管控和土地管理等环保措施有待进一步加 强, 以严格控制新生和环境遗留的污染物输人湖 泊,扭转当前污染趋势.

\section{3 结论}

近百年来太湖流域长荡湖富营养化和重金 属污染模式具有明显的阶段性, 主要受到流域不 同类型和强度的人类活动驱动. 1950 年之前, 湖 泊营养水平较低, 沉积物有机质受到内源和外源

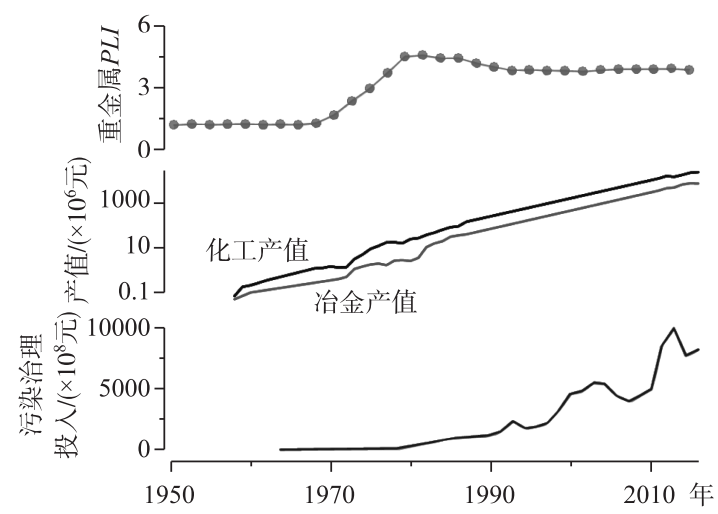

图 5 长荡湖岩芯沉积物重金属污染负荷与流域化工 和冶金产值及中国污染治理投人的历史变化对比

Fig.5 Historical variations of heavy metal pollution load index (PLI) in Lake Changdang, chemical and metallurgical product within the catchment, and investment in pollution treatment of China 共同影响,重金属以自然来源为主,反映了人类 活动影响较弱的准自然演化状态. 随后, 受农业活动和居民生活产生的营养输人影响, 湖泊逐渐开始富营养 化过程, 初级生产力上升, 内源有机质增加. 1970s 湖泊营养水平、藻类生产力和重金属污染程度均显著升 高, TP 含量快速升高 $(605 \sim 2050 \mathrm{mg} / \mathrm{kg}), \mathrm{Cd}$ 污染尤为严重 $(E F>40)$, 这与流域社会经济转型密切相关, 受 到粗放型发展模式下大量营养和污染物质排放的直接影响, 湖泊生态环境急剧恶化; 1980s 以后, 长荡湖在 多重人为驱动下已经大幅偏离自然演化基线, 维持在高度富营养化、重污染的状态. 最近数十年, 随着环境 保护和污染治理的投人, 湖泊生态环境质量略有提升,但流域排污管控、土地管理和生态修复等措施仍有待 进一步加强, 以满足区域可持续发展需求. 长荡湖长期演化模式与太湖流域其他湖泊类似, 共同表明, 深人 理解湖泊生态环境历史演变过程, 调控多重驱动影响和内在反馈, 有助于可持续的湖泊环境管理和生态 修复.

\section{4 参考文献}

[ 1 ] Qin BQ. Lake Taihu, China: Dynamics and environmental change. Amsterdam: Springer Science \& Business Media, 2008.

[ 2 ] Lin Q, Zhang K, Shen J et al. Integrating long-term dynamics of ecosystem services into restoration and management of large shallow lakes. Science of the Total Environment, 2019, 671: 66-75. DOI: 10.1016/j.scitotenv.2019.03.307.

[ 3 ] Taihu Basin Authority of Ministry of Water Resources ed. Taihu basin \& southeast water resources bulletin in 2019. Official Web of Taihu Basin Authority of Ministry of Water Resources, 2020. http://www.tba. gov.cn/slbthlyglj/szygb/content/ 54f58495-8964-4140-a01c-387b5d81fbac.html. [ 水利部太湖流域管理局. 2019 年度太湖流域及东南诸河水资源公 报. 水利部太湖流域管理局官方网站, 2020.]

[ 4 ] Jin XC, Liu HL, Tu QY et al eds. Eutrophication of lakes in China. Beijing: Chinese Research Academy of Environmental Sciences, 1990.

[ 5 ] Vinodhini R, Narayanan M. Bioaccumulation of heavy metals in organs of fresh water fish Cyprinus carpio (Common carp). International Journal of Environmental Science \& Technology, 2008, 5(2) : 179-182. DOI: 10.1007/BF03326011.

[ 6 ] Wang FF, Li XP, Chen XH et al. A study on the nutrition status evaluation and algal limiting factor in Lake Changdang during the last 15 years. Environmental Science and Technology, 2012, 35(S1) : 353-357. [王菲菲, 李小平, 陈小华等. 长荡湖近 15 年营养状态评价及限制因子研究. 环境科学与技术, 2012, 35(S1) : 353-357.]

[ 7 ] Zhao WH, Zhu Y, Zhu L et al. Change trend of water environment in Lake Changdang and main impact factors. Water Re- 
sources Protection, 2014, 30(6): 48-52. [ 赵苇航, 朱或, 朱亮等. 长荡湖水环境变化趋势及其主要影响因子. 水资 源保护, $2014,30(6): 48-52$.

[ 8 ] Shen J, Zhang K, Liu ZW. Paleolimnological evidence of environmental change in Chinese lakes over the past two centuries. Inland Waters, 2020, 10(1) : 1-10. DOI: 10.1080/20442041.2019.1657348.

[ 9 ] Shen J. Progress and prospect of palaeolimnology research in China. J Lake Sci, 2009, 21(3) : 307-313. DOI: 10.18307/ 2009.0301. [沈吉. 湖泊沉积研究的历史进展与展望. 湖泊科学, 2009, 21(3) : 307-313.]

[10] Lin Q, Liu EF, Zhang EL et al. Temporal and spatial variations in sedimentary characteristics of Lake Lugu during the hundred years and the influence fators analysis. J Lake Sci, 2017, 29(1) : 246-256. DOI: 10.18307/2017.0126. [林琪, 刘恩峰, 张恩楼等. 泸沽湖近代沉积环境时空变化特征及原因分析. 湖泊科学, 2017, 29(1): 246-256.]

[11] Du CC, Liu EF, Yang XD et al. Characteristics of enrichment and evaluation of anthropogenic pollution of heavy metals in the sediments of Lake Chaohu. J Lake Sci, 2015, 24 (1) : 59-66. DOI: 10.18307/2012.0108. [杜臣昌, 刘恩峰, 羊向东 等. 巢湖沉积物重金属富集特征与人为污染评价. 湖泊科学, 2015, 24(1): 59-66.]

[12] Zhang QH, Dong XH, Chen YW et al. Hydrological alterations as the major driver on environmental change in a floodplain Lake Poyang (China) : Evidence from monitoring and sediment records. Journal of Great Lakes Research, 2018, 44(3): 377-387. DOI: $10.1016 /$ j.jglr.2018.02.003.

[13] Lin Q, Zhang K, Liu EF et al. Deciphering centurial anthropogenic pollution processes in large lakes dominated by socioeconomic impacts. Anthropocene, 2020, 32: 100269. DOI: 10.1016/j.ancene.2020.100269.

[14] Dong XH, Bennion H, Battarbee R et al. Tracking eutrophication in Lake Taihu using the diatom record: Potential and problems. Journal of Paleolimnology, 2008, 40(1) : 413-429. DOI: 10.1007/s10933-007-9170-6.

[15] Zhang K, Yang XD, Kattel G et al. Freshwater lake ecosystem shift caused by social-economic transitions in Yangtze River Basin over the past century. Scientific Reports, 2018, 8: 17146. DOI: 10.1038/s41598-018-35482-5.

[16] Zhang YD, Su YL, Liu ZW et al. Sedimentary lipid biomarker record of human-induced environmental change during the past century in Lake Changdang, Lake Taihu basin, Eastern China. Science of the Total Environment, 2018, 613/614: 907-918. DOI: 10.1016/j.scitotenv.2017.09.185.

[17] Yang XD, Dong XH, Chen X et al. Past environmental changes and management suggestions for lakes in the Yangtze River economic belt. Bulletin of Chinese Academy of Sciences, 2020, 35(8): 977-987. [ 羊向东, 董旭辉, 陈旭等. 长江经济带 湖泊环境演变与保护、治理建议. 中国科学院院刊, 2020,35(8): 977-987.]

[18] Peng JX, Wu YN, Hu WP et al. The evolution characteristics of precipitation in the past 61 years at the lake Changdanghu. Resources and Environment in the Yangtze Basin, 2016, 25(2) : 292-299. DOI: 10.11870/cjlyzyyhj201602015. [ 彭俊 翔, 伍永年, 胡维平等. 长荡湖近 61a 降水量演化特征. 长江流域资源与环境, 2016, 25(2): 292-299.]

[19] Meng JY, Chen SM eds. Jintan County annals. Nanjing: Jiangsu People's Publishing, 1993. [孟济元, 陈书明. 金坛县志. 南京: 江苏人民出版社, 1993.]

[20] Chen X, Qiao QL, McGowan S et al. Determination of geochronology and sedimentation rates of shallow lakes in the middle Yangtze reaches using ${ }^{210} \mathrm{~Pb},{ }^{137} \mathrm{Cs}$ and spheroidal carbonaceous particles. CATENA, 2019, 174: 546-556. DOI: 10. 1016/j.catena.2018.11.041.

[21] Liu EF, Shen J, Yang XD et al. Spatial distribution and human contamination quantification of trace metals and phosphorus in the sediments of Chaohu Lake, a eutrophic shallow lake, China. Environmental Monitoring and Assessment, 2012, 184(4) : 2105-2118. DOI: $10.1007 /$ s10661-011-2103-x.

[22] Dung TTT, Cappuyns V, Swennen R et al. From geochemical background determination to pollution assessment of heavy metals in sediments and soils. Reviews in Environmental Science and Biotechnology, 2013, 12(4) : 335-353. DOI: 10. 1007/s11157-013-9315-1.

[23] Wu YH, Liu EF, Yao SC et al. Recent heavy metal accumulation in Dongjiu and Xijiu lakes, East China. Journal of Paleolimnology, 2010, 43(2) : 385-392. DOI: 10.1007/s10933-009-9337-4.

[24] Sutherland RA. Bed sediment-associated trace metals in an urban stream, Oahu, Hawaii. Environmental Geology, 2000, 39(6) : 611-627. DOI: $10.1007 / \mathrm{s} 002540050473$.

[25] Varol M. Assessment of heavy metal contamination in sediments of the Tigris River (Turkey) using pollution indices and multivariate statistical techniques. Journal of Hazardous Materials, 2011, 195: 355-364. DOI: 10.1016/j.jhazmat.2011. 08.051 . 
[26] Wu JL, Huang CM, Zeng HA et al. Sedimentary evidence for recent eutrophication in the northern basin of Lake Taihu, China: Human impacts on a large shallow lake. Journal of Paleolimnology, 2007, 38(1) : 13-23. DOI: 10.1007/s10933006-9058-x.

[27] Wu YH, Jiang XZ, Liu EF et al. The enrichment characteristics of mercury in the sediments of Dongjiu and Xijiu, Taihu Lake catchment, in the past century. Science in China: Series D: Earth Sciences, 2008, 51(6) : 848-854. DOI: 10.1007/ s11430-008-0051-2.

[28] Meyers PA. Preservation of elemental and isotopic source identification of sedimentary organic matter. Chemical Geology, 1994, 114(3/4) : 289-302. DOI: 10.1016/0009-2541(94)90059-0.

[29] Meyers PA. Applications of organic geochemistry to paleolimnological reconstructions: A summary of examples from the Laurentian Great Lakes. Organic Geochemistry, 2003, 34(2) : 261-289. DOI: 10.1016/S0146-6380( 02) 00168-7.

[30] Shen J, Liu ZW, Yang XD et al eds. Limnology. Beijing: China Higher Education Press, 2020. [沈吉, 刘正文, 羊向东 等. 湖泊学. 北京: 高等教育出版社, 2020.]

[31] Ge YW, Zhang K, Yang XD. Long-term succession of aquatic plants reconstructed from palynological records in a shallow freshwater lake. Science of the Total Environment, 2018, 643: 312-323. DOI: 10.1016/j.scitotenv.2018.06.203.

[32] Ellis EC, Wang SM. Sustainable traditional agriculture in the Tai lake region of China. Agriculture, Ecosystems \& Environment, 1997, 61(2/3) : 177-193. DOI: 10.1016/S0167-8809(96)01099-7.

[33] Li Y, Wang C, Zhu L et al. Characteristics of sediment pollution and eutrophication status of Lake Changdang. Environmental Science and Technology, 2005, 28(2): 38-40, 116. [李勇, 王超, 朱亮等. 长荡湖底泥污染特征及水体富营 养化状况. 环境科学与技术, $2005,28(2): 38-40,116$.

[34] Zhuge WL. The present situation of ecological environment in Lake Changdang and its countermeasures. Environmental Leader, 2000, (1) : 32-34. DOI: 10.1080/07266472.2000.10878600. [诸葛玮琳. 长荡湖生态环境现状及防治对策. 环境导报, 2000, (1):32-34.]

[35] Xu JH, Fu YY, Zhang X et al. A brief analysis of the present situation and existing problems of water ecology in Lake Changdang. Science to Breed Fish, 2020, (5) : 3-4. DOI: 10.2991/emehss-19.2019.55. [徐俊华, 付言言, 张响等. 长 荡湖水生态现状及存在问题浅析. 科学养鱼, 2020, (5) : 3-4.]

[36] Cheng HX, Li M, Zhao CD et al. Concentrations of toxic metals and ecological risk assessment for sediments of major freshwater lakes in China. Journal of Geochemical Exploration, 2015, 157: 15-26. DOI: 10.1016/j.gexplo.2015.05.010.

[37] N'Guessan YM, Probst JL, Bur T et al. Trace elements in stream bed sediments from agricultural catchments (Gascogne region, S-W France): Where do they come from? Science of the Total Environment, 2009, 407 ( 8) : 2939-2952. DOI: 10. 1016/j.scitotenv.2008.12.047.

[38] Zhu MJ, Tang L, Liu DQ. A review on monitoring and assessment of heavy metals in soils along major roads. Environmental Monitoring in China, 2015, 31(3): 84-91. [ 朱梦杰, 汤琳, 刘丹青. 交通干道沿线土壤重金属监测与评估综述. 中国环境监测, 2015, 31(3): 84-91.]

[39] Liao QL, Liu C, Wu HY et al. Association of soil cadmium contamination with ceramic industry : A case study in a Chinese town. Science of the Total Environment, 2015, 514: 26-32. DOI: 10.1016/j.scitotenv.2015.01.084.

[40] Zhang H, Shan BQ. Historical records of heavy metal accumulation in sediments and the relationship with agricultural intensification in the Yangtze-Huaihe region, China. Science of the Total Environment, 2008, 399(1/2/3) : 113-120. DOI: 10.1016/j. scitotenv.2008.03.036.

[41] Sarkodie SA, Strezov V. Empirical study of the environmental kuznets curve and environmental sustainability curve hypothesis for Australia, China, Ghana and USA. Journal of Cleaner Production, 2018, 201: 98-110. DOI: 10.1016/j.jclepro. 2018.08.039.

[42] Tian HZ, Zhao D, He MC et al. Temporal and spatial distribution of atmospheric antimony emission inventories from coal combustion in China. Environmental Pollution, 2011, 159(6) : 1613-1619. DOI: 10.1016/j.envpol.2011.02.048.

[43] Meybeck M. The quality of rivers: From pristine stage to global pollution. Global and Planetary Change, 1989, 1(4): 283-309. DOI: 10.1016/0921-8181 (89) 90007-6.

[44] Li AL, Beek TAD, Schubert M et al. Sedimentary archive of polycyclic aromatic hydrocarbons and perylene sources in the northern part of Taihu Lake, China. Environmental Pollution, 2019, 246: 198-206. DOI: 10.1016/j.envpol.2018.11.112. 